\title{
CHALLENGES AND STAKES OF THE POST-ACQUISITION INTEGRATION PROCESS
}

\author{
Mariana Vancea ${ }^{1}$
}

\begin{abstract}
Over the last few decades mergers and the acquisitions, both the international and the national ones, have become strategic instruments of growth and development of enterprises. A sensible aspect regarding the merger or the acquisition operations is that of integrating the entities had in view. Because it is considered that the high rate of the failure of the operations is due to unsuccessful integration of the entities, we have decided to identify the challenges occurring in this phase and the factors influencing mostly the integration process. Our research tackles aspects regarding the challenges resulting from a merger or acquisition operation, within the integration phase of the entities involved. Thus, we analysed the importance of the human and cultural factors and the challenges resulting from this integration process, for we consider that these factors have a strong impact on the post-acquisition performance and they can ensure the success of the integration. We found that the acquiring firms are affected by changes during the integration process, by retaining the important resources, the transfer of resources from or to the acquired firms and by eliminating the redundant resources. Yet, in the integration phase, the problems may occur due to human factors, cultural incompatibility and an inappropriate management of the integration process.
\end{abstract}

Key words: mergers and acquisitions, post-acquisition integration, organizational culture, human capital

JEL codes: $M 10$, M14

\section{Introduction}

Over the last few decades, due to the intensification of competition, of the new financial possibilities and the changes in the regulating process in all the countries, the mergers and the acquisitions, both the international and the national ones, have become strategic instruments favouring the increase of the product portfolios, the penetration of new markets of the purchase of new technologies. The decision to apply the merger or acquisition operation often represent one of the most important actions subordinated to the strategy of an enterprise, having immediate financial implications yet, important consequences on long term (in terms of development and survival).

A sensible aspect regarding the merger or the acquisition operations is that of integrating the entities had in view. Thus, many researchers consider that integration is the most important phase of the merger or acquisition process. Hence the idea that the failure of a merger or acquisition operation is mainly due to the unsuccessful integration of the entities. Considering that the high rate of the failure of the operations is due to integration, we have decided to identify the challenges occurring in this phase and the factors influencing mostly the integration process. Thus, after a short description of the research methodology used in this paper, we presented the main research studies in the literature on the post-acquisition or post-merger integration. Also, we presented different integration policies and then the stakes of the post-acquisition management. We analysed the importance of the human and cultural factors in the integration process and the way in which a firm can manage these factors so that they ensure the success of the integration. In the end we presented a few conclusions of the research.

\footnotetext{
${ }^{1}$ University of Oradea, Faculty of Economnic Sciences, Romania, e-mail: mavancea@uoradea.ro
} 


\section{Research Methodology}

The study of literature in the field provides the theoretical base regarding the post-merger or post-acquisition integration. Considering that the field of mergers and acquisitions is extremely extensive, we selected the relevant papers on the post-acquisition or post-merger integration, in other words, a total number of 41 scientific papers and books, covering the period 1986-2009. Our research tackles aspects regarding the challenges resulting from a merger or acquisition operation, within the integration phase of the entities involved. Thus, the first part of the research presents conceptual delineations regarding the post-merger or post-acquisition integration and it further presents different integration policies which can be adopted after the on-coming operation. The following discussions refer to the stakes of the post-merger or post-acquisition management. Thus, we analysed the importance of the human and cultural factors and the challenges resulting from this integration process, for we consider that these external factors can have a stronger impact on the post-acquisition performance than the external strategic factors. The post-acquisition integration represents a critical phase of the operation and it has a major influence on the of the new group's performance.

\section{A short review of the literature on post-acquisition integration and the different integration policies}

The terms ,post-acquisition" or "post-merger" mainly refer to the art of combining, not only on the paper, but also in reality, two or more companies after these have come under common ownership. The integration refers to the combination of several elements, such as the accounting systems, the assets, the production lines, the information technologies or the cultures. Not all these elements are integrated or perhaps it is not necessary for the organization to work properly.

The most sensible phase of the entire merger or acquisition process is that of integrating the acquired merged enterprise for this is the moment when all the previous efforts and all the previous precautions can be definitely ruined (Delecourt and Fine, 2008). The challenges of the integration follow from different cultural values and behaviour norms of the players involved in this process and the difference between the two enterprises (Abhijit and Hajro, 2009).

The integration consists in the coordination and control of the entities making the group and the management of the conflicts in terms of objectives in order to get the expected results on the whole. Yet, it is a difficult task for it requires the reunion of the entities which used to be independent until that moment. This phase is strongly related to generating synergies which require a combination determining changes difficult to handle: the relocation of a part of production, the development of a common informational system, staff movements, redundancies, the coordination of commercial policies etc.

The post-acquisition integration is the interactive and gradual process of strategic and administrative combination of the acquiring enterprise and the acquired enterprise (Shanley and Correa, 1992), where the individuals of the two organizations learn to work together and cooperate in order to transfer strategic competencies (Haspeslagh and Jemison, 1991). The acquisition process is multidimensional, including the integration of the financial, informational, human resources, acquisition, production, marketing and distribution systems and the planning system, the public relations policies or the corporate cultures (Sherman and Hart, 2006). During the integration process the managers have to call up each department to act together within the new entity formed postmerger or post-acquisition. The integration represents the engine for organizational change and development afferent to firms' growth through acquisitions and it plays a major role in the corporate renewal strategy. The process changes the organizational structures, the systems, the functional cultures and activities at the level of the entire corporation strategy (Pablo, 1994). This process requires the post-acquisition reconfiguration (Karim and Mitchell, 2000), the common use 
(Capron et al, 1998) and the elimination (Capron et al, 2001) of certain tangible and intangible resources of the target company.

The integration may target all the dimensions of the organizations among which the oncoming takes place: the activities of different departments, physical activities, structure, culture and management. Having common history and experiences, the members of an organization have the tendency to develop a culture translated into attitudes, ways of thinking, interactions, organization logic and specific strategic considerations. The corporate culture depends on the geographical position of the enterprise as well as on the culture of the country of origin. Also, it is defined by several elements related to the enterprise's development cycle and the attitudes of its members in the work context (mangers, shareholders, employees).

In the case of merger and acquisition operations, the corporate culture reflects an essential aspect for the operation chances to succeed. This analysis allows the identification of the elements specific to each entity and of the risks generated by the too obvious differences or incompatibilities. The more different the cultural characteristics of the two enterprises are, the higher the risks. Actually, an enterprise is seldom culturally chosen for what it comes first are the strategic or financial motivations. Therefore, the acquirer discovers this reality after the operation and the integration phase is where these cultural differences appear.

It is obvious that the success of a merger or acquisition operation is strongly related to a cultural management of the entities and also to the taking into consideration of the psychological impact of the operation on the members of the acquired enterprise.

In the literature, several studies have examined the post-acquisition integration. The problems tackled with refer to the way in which the acquiring firms retain, use in common, reconfigure, and capture resources (Capron, Dussuage and Mitchell, 1998; Capron, Mitchell and Swaminathan, 2001; Finkelstein and Halebian, 2002; Karim and Mitchell, 2000), the past of the organization and the human processes occurring in the phase of post-acquisition integration (Fried, Tiegs, Naughton and Ashford, 1996; Greenwoog, Hinings and Brown, 1994; Scweiger and DeNisi, 1991) or the choice of the extent of integration (Datta, 1991; Pablo, 1994).

The evaluation of a merger or acquisition operation is carried out according to the acquirer's capacity to carry out in good conditions the integration of the acquired enterprise. The postacquisition period is not yet risk lacking. It involves a detailed management of the cultural and human aspects of the operation. Also, it requires the association of the methods of integration implementation with the objectives of the acquisition, considering the characteristics of the acquired enterprise. For the acquirer, the integration requires thus an extremely sensible period to manage when it is necessary to capitalize the valuable creation potential of the new whole. Only an efficient management, centred on the understanding of the cultural and human problems allows the achievement of this objective.

The importance of the post-acquisition integration becomes obvious in the following statement belonging to the researchers Haspestagh and Jemison (1991):

"Many acquisitions look great on paper. Yet, no matter how attractive the opportunity, value is not created until after the acquisition when capabilities are transferred and people from both organizations collaborate to create the expected benefits or to discover others."

One of the first models of the process of cultural adaptation and acculturation, in the operations of merger and acquisition, was presented by the researchers Nahavandi and Malekzadeh (1988). The central idea of the model is that the degree of congruence between the favoured integration modes of the acquirer and of the acquired company will influence the success of this operation's implementation. The acculturation model is determined by the cultural characteristics and the porganizational strategies of the two enterprises involved in the approaching process. Therefore, from the point of view of the acquired company, the favoured acculturation mode will be determined by the extent to which the members of the organization wish to keep their own corporate culture and the extent to which they are open to adopting a new culture, that of the 
acquiring company. From the point of view of the acquirer, the culture and especially the extent to which the enterprise values multiculturalism, as well as the diversification or specialisation adopted strategy, will determine the favoured acculturation mode. The second variable of the acculturation process is represented $\mathrm{b} y$ the nature and intensity of the connections between the two enterprises. Thus, in the case of the enterprise mergers or acquisitions in a related field, the chances for the acquirer to impose its own corporate culture are much higher than the situation when the two businesses are not related. Therefore, according to these variables, it can be opted for one of the four acculturation strategies possible: integration, assimilation, separation, and acculturation.

The integration requires the combination of the two cultures through a reciprocal influence. The assimilation requires the adoption by the enterprise of the other's culture and identity. The separation requires the preservation of the culture and identity of each enterprise. The acculturation/marginalization reflects the wish of the acquirer to impose its own culture which comes against the resistance of the acquired company. From this confrontation there results a loss of the culture of the acquired company and the actual non-integration in the new whole.

Thus, the central idea of the acculturation model built by Nahavandi and Malekzadeh is that, considering the fact that the members of the two organizations might have different preferences for the acculturation mode, the extent of the agreement (congruence) regarding these preferences will represent a central factor to successfully implement the integration. The higher the matching to the level of preferences is, the more reduced the level of the acculturation stress will be, the lower the resistance to change and the change will take place easier. Then incongruence occurs when the two organizations do not have the same preferences regarding the acculturation mode which will increase the acculturation stress, both individually and organizationally. Following this situation, certain key employees may leave the organization which is a loss of competences and, also, it may appear the active resistance to the attempt to impose the acquirer's systems.

Phillipe Haspeslagh and David Jemison (1991) identified three approaches of the postacquisition integration: preservation, integration through asset rationalization (absorption) and symbiosis $^{2}$.

\begin{tabular}{|c|c|c|c|}
\hline \multirow{4}{*}{$\begin{array}{l}\text { Need for } \\
\text { organizational } \\
\text { autonomy }\end{array}$} & & \multicolumn{2}{|c|}{ Need for strategic interdependence } \\
\hline & & Low & High \\
\hline & Low & Preservation & Symbiosis \\
\hline & High & (Holding) & Absorption \\
\hline
\end{tabular}

Figure no. 1. Types of integration policies

Source: Haspeslagh, P. and Jemison, D.B. (1991), Managing Acquisitions- Creating Value Through Corporate Renewal, Free Press, London

These approaches of integration can be better understood by considering the two central dimensions of the acquisition. The first dimension refers to the relation with the acquiring firm, more precisely to the interdependence which must be established between companies in order to realise the strategic capability transfer that is expected. Furthermore, Haspeslagh and Jemison (1991) stated that the capability transfer represents the value creation source in a merger or acquisition operation: "Acquisitions create value when the competitive advantage of one firm is improved through the transfer of strategic capabilities".

The second dimension refers to the way in which value is expected to be created. This is associated with the need to preserve intact the acquired strategic capabilities. The figure above

\footnotetext{
${ }^{2}$ Symbiosis represents those interactions whose main purpose is to create reciprocal and durable advantages, based on the diversity of the entities and requiring in the same time preservation and interdependence.
} 
positions integration processes in light of the relationship between these two dimensions that vary according to an entity's need for organizational autonomy and strategic interdependence.

The preservation integration means the preservation of the culture of the acquired enterprise and the granting of management autonomy in the operational field. In this case, the managerial influence of the acquirer is rather weak, the managers of the acquired unit being actually evaluated according to their results. Therefore, the success of such policy resides in the capability of the acquired enterprise to give zest to a major growth, with a return on investments superior to the sums invested (Meier and Schier, 2006). The preservation integration occurs in the case of the external growth operations through mergers and acquisitions whose main objective is to penetrate new markets where the initiating enterprise does not have the necessary capabilities and when it is required the getting of new strategic capabilities (Bancel and Duval-Hamel, 2008). This integration policy is better adapted to the cases of some acquisitions subordinated to a diversification strategy (Meier and Schier, 2006). The purpose of the operation is to integrate new activities, susceptible of renewing the portfolio of activities. Haspeslagh and Jemison suggested the fact that this integration policy is a way to update the resources of the corporation when the acquiring firm intends, for instance, to take over certain knowledge, capabilities, from the acquired firm.

The absorption integration is recommended when then management and administration ways of the acquired company are not intended to be kept (Bancel and Duval-Hamel, 2008). This integration policy is meant to reorganize the resources of the acquirer and of the acquired enterprise within a new whole mainly based on the procurement of scale and scope economies, on the smoothing of the managerial practices and the strengthening of the competitive position (Meier and Schier, 2006). Certain acquisitions are realised from rationale related to the closeness of activities or their complementarity, intending to realise synergies. Thus, the existence of strong strategic connections, corroborated with the lack of specificity, leads to a tight closeness between organizations, which pass through an absorption integration process (Meier and Schier, 2006). This integration policy is realised in the easiest manner and is usually used when a large firm is acquiring a smaller competitor. The diminishing of the costs and the volume effects represents the benefit mentioned, regularly, in this type of operations. In spite of the fact that the homogenization actions often favour the acquirer it might happen and sometimes it is desired, that the new whole can take the qualities of each party, obeying an efficacy logic (specific capabilities) and also of efficiency (time and cost gains). Therefore, the absorption integration cannot be assimilated to domination against the acquired unit. The differences can indeed prove to be sources of competitive advantage for the new whole. The absorption integration is often initiated by the acquirer who shapes the new whole, according to its principles and in its favour. This integration policy is explained more often due to the similar activities and the existence of duplicate activities which give meaning to a rationalization strategy. This situation often leads to the occurrence, more or less visible, of an identity of the acquired unit which sees its organization profoundly changed and its main identifying elements removed. Such an asymmetry may generate rivalries within the organization (Meier and Schier, 206). Actually, the enterprise having the strongest leadership or which it has got a favourable force ratio will impose its own culture (Bancel and Duval-Hamel, 2008).

The symbiosis type integration is the management of contradictory exigencies. This integration policy is extremely complex for it targets the progressive adaptation of the acquired company, leaving a certain organizational autonomy not to reduce its competitivity level (Bancel and Duval-Hamel, 2008). It is about studying the way in which the interdependencies between the strategic activities of the two firms must be realised without destroying the value creation potential. Hence, it is necessary in this configuration to keep the identity of the acquired unit (that of the acquirer being, obviously, less threatened), determining the progressive evolution of the two units to the creation of new and distinctive advantages. The attention given to each firm's own qualities (and therefore to their cultures) distinguished the symbiosis policy from the absorption integration, while the development of the deepened operational relations makes it different from the 
preservation integration. This type of integration is, by far, the most sensible case to manage (Meier and Schier, 2006). Different styles and cultures, the positions of winners and losers and the operational difficulties within the close systems make the implementation of this integration policy extremely difficult.

The holding ${ }^{3}$ type integration has in view the procurement of a lower degree of strategic interdependence and also of a low level of organizational autonomy.

Haspeslagh and Jemison analysed acquisitions from a process-like perspective, which changes the orientation from the results of the acquisition to the factors determining these results. Value creation is considered a performance resulting from the managerial actions and the interactions among the firms. From their point of view, the capability transfer will lead to getting a competitive advantage or, in other words, to value creation. Thus, they consider that the postacquisition integration plays an important role in determining the results of the acquisition.

The choice of the management regarding the integration level depends on the level of financial control obtained. In other words, if through the merger or acquisition operation a limited control is obtained, the integration level will be weak, even inexistent. Yet, if the financial participation is important, the integration will be real.

Bancel and Duval-Hamel (2008) consider that enterprises mostly adopt hybrid integration strategies, often representing mixes of the certain integration methods. Therefore, the same merger or acquisition operation can be managed by a combination of two styles: at the corporate level where there is a transfer of the culture and the organization mode from the acquiring company to the target company, and, at the operational level, the management is that of "cold war" type by complying with the specific of each enterprise.

The integration level depends on the strategic (Pablo, 1994; Shrivastava, 1986), organizational (Datta, 1991; Jemison and Sitkin, 1986), cultural (Nahavandi and Malekzadeh, 1988) and political characteristics (Pablo, 1994) of the merger and acquisition operations. For the unrelated operations generally involve a minimum blend of resources and therefore a low postacquisition integration, the related operations between the acquirers and target companies often lead to high integration levels (Shrivastava, 1986).

The challenges of the integration process occur due to the multidimensionality and diversity of the tasks to fulfil within this phase of the merger or acquisition process. Integration means the synchronization of the efforts in the financial field, of human resources, marketing and production.

The success in the post-acquisition period requires an approach in phases with well-defined objectives and actions. The management of cultural and organizational integration requires caution and reciprocal concord so that conflicts are avoided (Quah and Young, 2005).

The company formed as a result of merger or acquisition $n$, having a new organization chart and a new form of organization must act on all the functional levels: administrative, structural, strategic, managerial, and operational. Several enterprises will favour the internal operational resetting, neglecting the external pone. It is necessary to also invest externally and to develop a real external integration targeting the group of stakeholders (clients, suppliers, media, trade unions etc.) and of shareholders.

\section{The stakes of the post-acquisition management}

The growth of the firms through mergers and acquisitions has become a regular policy of enterprise which, in spite of efforts, continues to record deceptive results too for the parties involved. These unsatisfying results made that the research performed in the field be more and more based on the integration period. Indeed, recent works emphasize the need that, beyond the control of

\footnotetext{
${ }^{3}$ The appearance of hodlings dates from the end of the 19th century when New Jersey, an American state, sanctioned the existence of corporations having as purpose only the acquistion of shares from other enterprises.
} 
the decision and negotiation processes, a special attention should be given to the phase following the acquisition action that is the integration phase.

The studies referring to the integration period have evolved immensely together with those trying to show that one of the conditions for a merger or acquisition to be successful is represented by the control of the integration process (Haspeslagh and Farquhar, 1987; Jemison, 1988; Jemison and Sitkin, 1986). These studies suggest the existence of a possible connection between the integration process of the acquired units and the results of the operation. From this perspective, the success of the operation should not be reported only to the either cultural or organizational differences or incompatibilities. This requires an analysis of the value creation process. In this way, the researchers have given a new dimension to the post-acquisition phase, establishing a strong connection between the integration process and the value creation process. The mode to analyse and understand the management of the integration process indeed consists in the players' capability to manage, according to the objectives of the acquisition, the strategic interdependences and the needs for organizational autonomy between the units.

The post-acquisition integration is a complex process whose management is centred on a necessary change. The particularity of this change, contrary to what is going on during enterprise re-engineering, consists in the fact that it involves the employees of the two different enterprises: the acquirer and the target company. Both of them, but especially those of the target company, are forced to integrate themselves within the same social-professional environment, which represents the direct consequence of the merger or of the acquisition. Bancel F. and Duval-Hamel J. (2008) consider that the stronger the corporate culture is, the more complicated the integration phase will be and the more attached to their corporate culture the employees are, the more difficult the integration of a new culture will be. As a result of different cultures of the two units, this postacquisition or post-merger integration is characterised by different interactions which lead to some strongly divergent situations. In a favourable case, these interactions are the link of all the resources gathered together and thus they might create value. Yet, many times, these interactions create dysfunctions within the organization, complicating even further the integration process (Gouali, 2009).

Gouali M. considers that the enterprises managing to integrate share several key elements (Gouali, 2009):

- The wording of a clear vision regarding the problems to be solved and the preparation even from that moment of the solutions and all these concomitantly with the decision making process to carry out a merger or acquisition operation;

- The assurance that certain successful factors are used and which are necessary when engaging in a merger or acquisition operation:

- The possession of internal mechanisms, expertise and know-how regarding the carrying out of the change and especially the management of the adaptation to the new conditions;

- The management of the competition amelioration processes until saturation, through innovation, development of new markets, the efficiency of the commercial forces, the management of the relation with the clients, the reconfiguration of the unsatisfying processes etc.

An appropriate change management within an organization can be carried out only by an appropriate communication at the organizational level. Young and Post (1993) showed in their study that communication is very important to make the employees less resistant to change. Moreover, the results obtained by them indicate that the initiative of the communication must come from the top management and that it must be continuous for the entire period of change. Also, it is vital there is not any discrepancy between words and deeds. Therefore, communication is an important instrument to manage a change such as a merger or an acquisition (Scweiger and DeNisi, 1991). 
Even from the first contacts with the target company and to the end of the integration period, the acquirer must, first of all, apply the communication strategy and different tactics especially chosen for this purpose. Communication represents a central pillar of the pre and post-acquisition processes, from the beginning of the operation to its end. Communication requires in the same time the broadcasting of insertions, the psychological approach of employees in order to adapt them to the new context and also an influence strategy to mobilize and co-interest the employees in order to achieve the objectives (Gouali, 2009).

\section{The importance of the cultural factors in the post-acquisition process}

Corporate culture is considered a lever whose use becomes crucial for the success of the integration period. Corporate culture can be defined as the assembly of attributes and values shared by the employees and which dictate the latter's professional and moral attitudes. The component elements of the corporate culture are represented by its history, its activity, brand, the organization mode, and its ethical norms. These aspects represent the values around which the identity of the enterprise is built (Gouali, 2009). O'Reilly and Chatman (1996 quoted by Abhijit and Hajro, 2009) defined the corporate culture as "a set of norms and values widely shared and intensely held throughout the organization a system of shared values and norms that define appropriate attitudes and behaviours for organizational members". The values define what is important and the norms define the appropriate behaviours of the organizational members.

In the literature on the post-acquisition integration, the cultural incompatibility is considered as a source of the problems occurring in this phase (Nahavandi and Malekzadeh, 1988; Olie, 1994). Therefore, the cultural incompatibility is considered a cause for the weak performance of the merger and acquisition operations, for the departure of some key players and for the conflicts occurring during the business consolidation process (Bijilsama-Frankeman, 2001). BijilsamaFrankeman (2001) considers that the collocation "culture clash" was worded out in order to describe the conflict of the philosophies, styles, values, and mission of two companies. Due to the multitude of changes generated by the merger or by the acquisition, the post-acquisition period presents many adjustment problems. The most majority of these adjustment problems comes from the employees' fears concerning the loss of their jobs. The change of the managers and of the work team is also a source of stress and anxiety (Marks and Mirvis, 1992).

The corporations facing such problems have to pay the high price of losing the cooperation and initiative of the new organization's employees. The synergies previously announced may become difficult to obtain, the conflicts and misunderstandings can be difficult or even impossible to solve and therefore the post-acquisition period will be the most difficult to manage (Appelbaum et al, 2000).

Generally, the cultural aspects are not taken into consideration when a merger or acquisition operation is initiated, but only the strategic and financial aspects are targeted. And yet, in literature, many studies (Buono et al, 1985; Datta, 1991; Chatterjee et al, 1992; Cartwright and Cooper, 1993; Weber, 1996 or Morosini et al, 1998) consider that the cultural differences at the organizational and national level are one of the main causes of the high rates of the failure of merger and acquisition operations. Lacking a well defined integration policy and a cultural homogenization, any cultural difference between the enterprises may create antagonisms and create dysfunctions affecting the performance of the new group. There are three strategies to approach the cultural differences (Gouali, 2009):

- Imposing one of the two cultures: this solution is feasible but its success requires a rapid execution and based on tasks with a high symbolical meaning: its immediate adaptation to the working methods, the participation and adaptation to the style promoted by the enterprise.

- Creating a new culture: this solution is possible, but risky because it might eradicate two communities and create a new culture, in which none is to be found. 
- Maintaining the two cultures.

In practice it has been noticed that the two cultures dominate and this is that of the acquirer's. The example of the company Sanofi-Synthelabo is significant in this view. Acquiring the company Aventis, the general management immediately imposed to all the participant parties, a common culture. Thus, the acquirer especially forced the impregnation with a culture of confidentiality which has become dominant at the group level. The employees of Aventis rapidly adapted to the new requirements, creating a certain harmony at the group level. Obviously, the key factor for the success of these strategies consists in taking into consideration the aspects representing advantages of the culture of target company and ensuring its success (Gouali, 2009). Schein (1993) states that, yet, a corporate culture seldom has values and beliefs shared by all the organizational members. In exchange, this can contain different subcultures which can sometimes be even contradictory.

The cultural diagnosis may represent a means to perceive the culture of an enterprise and to identify the risks related to the confrontation between different origin cultures. Indeed, the culture of the enterprise groups coherently the values and the beliefs commonly accepted by the majority of the organizational members. Certain cultures, for instance, wager on the entrepreneurial spirit and action, while others favour the management of commercial and financial risks. The incompatibility between certain values or beliefs and therefore, the cultural distance can create strong imbalances within the new whole.

A study of the consulting company MMC (Marsh \& McLennan Companies) mentions that the corporate culture differences are considered one of the most significant challenges in a merger or acquisition operation and that in any transaction, the key is to identify and consolidate the behaviour models with a positive influence regarding the success of the operations and in the same time tom discourage those eroding value (Carpenter and Wyman, 2009).

The researchers examined the behaviour changes resulting from the compulsive interaction of two different corporate cultures. Certain empirical studies indicated that the big cultural differences lead to bigger problems regarding the integration and, therefore, to a weaker postacquisition integration (Chatterjee et al, 1992; Datta, 1991). On the other side, the existence of such a strong culture of the acquirer may have an impact on its performance if this can be transmitted effectively to the acquired company. The unanimous consensus is that, generally, the cultural compatibility reduces the acculturation stress and makes the integration process easier.

Generally, the cultural shocks appeared occurred during the closeness operations between enterprises are reflected on three main levels (Meier and Schier, 2006):

- Conflicts at the level of structures and working systems (control, remuneration, recruitment, motivation, delegation etc.)

The structures of the enterprise represent in the same time the architecture and the essence of the organizations. They generally reflect the fundamental aspects of the enterprise, the way resources are managed as well as the each person's responsibilities within the firm.

- Conflicts related to the management style (values, philosophy, managerial practices, The management style allows to see the key values and the guiding concepts on which the actions undertaken at the company level are based. Thus, defining the management style allows the employees to have an orientation system ensuring them stability and which stimulates them. This contributes to the inculcation of a way of life and behaviour favouring the mobilization and implication of the employees in their work. The management style of each enterprise must be clearly identified and understood. The enterprises follow the identification of the official and unofficial working modes, of the real power areas, of the evaluation criteria of individual and collective performances and the resistance to the merger or acquisition operation. These aspects allow removing 
the uncertainties, to see the advantages and the practices that must be preserved (Bancel and Duval-Hamel, 2008).

- Conflicts related to exercising the power within units

Exercising the power may take different forms, according to each enterprise. For certain organizations, power is strongly connected tom the hierarchical position of the actors within that particular system. Exercising the power is based on a formal authority system (status, hierarchical level) and the individuals' capability to dispose of a coercive influence. In other systems, the power of the players consists more in the capability to master certain resources, in its personality and its relational experience. Actually, when approaching an enterprise, exercising the power may generate strong oppositions and can make the object of a litigation procedure between the two organizations.

The cultural dimension is unanimously considered important even crucial in the success of the merger or acquisition operations. Bancel and Duval-Hamel (2008) consider that a double strategy regarding the corporate culture must be applied. First of all, a "formal culture" must be defined and applied, mainly, destined to the internal and external communication in order to create the image and identity of the new company resulted from the merger or acquisition operation. This is defined by the members of the company management. Second of all, an "operational culture" must be defined and applied, destined to the internal structuring. Its drawing up process is much more open, implying both the management and the players involved. The combination of the two cultures and their application requires the assurance of the integration of the two units and thus, the accomplishment of the merger and acquisition operation. The formal and operation drawing up process and, generally, the set of the integration actions, is quite complex.

\section{The importance of the human factors in the post-acquisition integration process}

More and more research studies (Hogan and Overmyer-Day, 1994) concentrated on the human side of the merger and acquisition operations, exploring the problems related to the organizational matching and the organizational integration problems.

Many managers of acquiring units tend to minimize the importance of social and human problems when they perform the external growth operation, in spite of the risks they have in the integration phase (Meier and Schier, 2006). It proves to be of essence the creation of a reliable and morally support climate for the individuals in managing the inherent stress occurred as a result of the changes generated by the merger and acquisition operations. This support allows the limitation of the negative effects on labour productivity (Bancel and Duval-Hamel, 2008).

The human factor plays a main role in the success of the integration phase and this success is perceptible on two levels. First of all, the success implies a new psychological and organizational environment after destructing the one the employees of the units belonged to. From the emotional point of view, this change is not neuter for the uncertainty vehiculated by change plays an important role in demotivating the employees, no matter their hierarchical level. In the second place, the success of the integration requires the rapid adaptation of the employees to the new requirements of the enterprise including the subordination to its objectives, the adaptation to new work methods, the interiorization of the corporate culture which is to be adopted, the management style etc. The success of the integration phase requires the setting up of continuity between the two levels and the management of the interdependencies of their elements. In other words, these two levels, when well managed, create a solid support for the transformation of synergies into value. Conversely, one of the causes of the failure of integration originates in the de-correlation between the two levels. The lack of focus on one or another leads to frustrations, deviates resources, reduces the competitivity of the key activities and affects the global efficiency of the transaction. . The main stake of this phase consists in combining these two levels' own successful factors so that they can reach the profitable growth objectives (Gouali, 2009). 
The literature on human resources and organizational behaviour abounds in researches regarding the human, managerial, and organizational processes occurring within the process of resource adding and reconfiguration (e.g. Cannella and Hambrick, 1993). In these studies the human and organizational sources are identified as elements resisting the integration. Indeed, the human and organizational factors may have a stronger impact on the post-acquisition performance than the external strategic factors (Chakrabarti, 1990). The acquiring firms underestimating the importance of human factors in the integration phase might face high obstacles in managing the post-acquisition operations as it has been showed by Fried et al. (1996), Greenwood et al. (1994), Schweiger and DeNisi (1991).

The research (e.g. Scweiger and DeNisi, 1991) shows that the announcements of firm acquisitions, especially of those characterised by a weak communication, increase uncertainty, stress and absenteeism, in the same time with the diminishing of the satisfaction level regarding work, commitment, the intention to stay in the new organization and the perception on the organization's credibility. Haspeslagh and Jemison (1991) state that"The threat of acquisition may reduce or destroy important economic or psychological elements such as job security, promotion, career opportunities, status and pride regarding the membership to the organization”.

Bourantas and Nicandrou (1998) developed a conceptual framework in order to explain the behaviour of the employees in the acquired company, after the acquisition operation. The model contains two dimensions: support/resistance and activity/passivity. The first dimension refers to the fact that the employees will have a reaction of support if they accept the changes implemented by the new managerial team. In exchange, if they do not accept the change, they will continue to oppose. The second dimension refers to the relation between the organization that is the effort of the employees regarding the creation and maintenance of work relations during the post-acquisition phase. The two authors further consider that after an acquisition operation, the employees either support the organization, working more (loyalty) or continue working like before the change (complacency), or they try to change certain aspects by expressing their opposition (opposition), or they reduce the effort at work (slovenly). The dimensions reflecting the loyalty and the opposition regarding the acquisition are considered active behaviours and the complacency and the slovenly are considered passive behaviours.

The post-acquisition changes often involve a forced workforce redundancy and reorganizations in order to reduce the costs and the excess of workforce. The impact of such organizational changes on the employees is high, the latter considering that they have no control on the changing forces. These employees are susceptible to feel uncertainty regarding their jobs, helplessness, demotivation which can generate the intention to leave the organization, as Fried et al. (1996) showed.

In light of these, we consider that the human and organizational factors may have a higher impact on the post-acquisition performance than the external strategic factors. Therefore, the acquiring firms may face important obstacles in managing the post-acquisition operations.

\section{Conclusions}

The post-acquisition integration represents a critical phase of the operation and it has an important influence on the new group's performance. The acquiring firms are affected by changes during the integration process, by retaining the important resources, the transfer of resources from or to the acquired firms and by eliminating the redundant resources. Yet, in the integration phase, the problems may occur due to human factors, cultural incompatibility and an inappropriate management of the integration process.

From the analysis of the integration/acculturation models presented in this research report, we can draw several conclusions. In the first place, the corporate culture of the enterprises involved influences the preference for a certain integration strategy and the congruence between the participants regarding the strategy chosen represents one of the factors ensuring the success of the 
merger and acquisition operations. In the second place, due to the fact that the acculturation strategies imply several different integration levels of the combination between the two enterprises, the impact of the corporate culture will be higher in the case of the combinations requiring a high level of integration and change than in the case of those in which the organizations remain relatively independent. Thus, the human factor will more affected when a high integration level in comparison with the integration form favouring the units' independence. In the third place, the evaluation of the cultural adjustment level is not a sufficient condition to foreshadow the results of the integration process. The integration strategy and the changes at the level of corporate culture influence the organizational practices, which leads to different reactions of the employees directly influenced by them. Therefore, a series of dynamics may occur during this process, dynamics which will significantly influence the results of the integration in terms of organizational members' reactions.

An important aspect we wished to identify refers to the strategies that an enterprise may adopt regarding the cultural integration. Thus, even if theoretically after an approaching operation it can be opted for the creation of a new culture, the maintenance of the two cultures or the enforcement of one of the two, in practice, it has been noticed that one of the two cultures dominates and it is the acquirer's. Therefore, we identified the levels the cultural shocks occurred during approaching operations reflect to and the way in which these could be managed.

Regarding the human factors, we emphasised the impact that the merger and acquisition operations have on them, the way in which these changes are perceived by the employees and the attitude concerning the change that these may lead to after the operation.

Thus, we can state that the post-acquisition or post-merger integration is the phase when the expectations are fructified or, on the contrary, ruined. The architecture of the merger or acquisition transaction and its terms create conditions for this crucial phase of the operation. Not identifying the problems related to the integration may generate important dysfunctions in the following phases. Thus, it is important to know beforehand what is next after the final signing of the merger or acquisition contract for the chances of success of the integration operation to be higher.

\section{References}

1. Abhijit M., Hajro Aida, 2009. Integration in cross-border mergers and acquisitions, The 27th International Conference of the System Dynamics Society, available on-line: http://www.systemdynamics.org/conferences/2009/proceed/papers/P1246.pdf, accessed 04.03.2011

2. Appelbaum S.H., Gandell J., Yortis H., Proper S., Jobin F., 2000. Anatomy of a merger: Behavior of organizational factors and processes throughout the pre-during-post-stages (part 2), Management Decision, 38 (10), pp. 674-684

3. Bancel F., Duval-Hamel J., 2008. Fusions d'entreprises: Comment les gerer, comment les vivre, Eyrolles, Editions d'Organisation, Paris

4. Bijilsama-Frankeman F., 2001. On managing cultural integration and cultural change processes in mergers and acquisitions, Journal of European Industrial Training, Vol.25 (2-4), pp.192-207

5. Blanchot F., Le Management Stratégique des Fusions-Acquisitions: Motifs, Effets et Conditions de Réussite, in Meier, O.(ed.) (2009), Stratégies de croissance, Editeur Dunod, Paris

6. Bourantas D., Nicandrou I.I., 1998. Modelling Post-Acquisition Employees Behavior: Tipology and Determing Factors, Employee Relations, nr.20(1), pp.73-91

7. Buono P.J., Bowditch J.L., Lewis J.W., 1985. When Cultures Collide: the Anatomy of a Merger, Human Relations, Vol.38, 5, pp.477-500

8. Cannella A.A., Hambrick D.C., 1993. Effects of Executive Departures on the Performance of Acquired Firms, Strategic Management Journal, Vol.14, pp. 137-152 
9. Capron L., Dussuage P., Mitchell W., 1998. Resource redeployment following horizontal mergers and acquisitions in Europe and North America, 1988-1992, Strategic Management Journal, nr.19, pp.631-661

10. Capron L., Mitchell W., Swaminathan A., 2001. Asset diversiture following horizontal acquisitions:a dinamic view, Strategic Management Journal, nr.21(10-11), pp.1061-1081

11. Carpenter G., Wyman O., 2009. The impact of culture on M\&A. Dong something about it, available on-line:

http://www.mmc.com/knowledgecenter/Mercer_impactCultureM\&ATransactions.pdf, accessed 04.03.2011

12. Cartwright S., Cooper C.L., 1993. The Role of Culture Compatibility in Sucessful Organizational Marriage, Academy of Management Executive, vol.7, 2, pp.57-70

13. Chakrabarti A.K., 1990. Organizational factors in post-acquisition performance, IEEE Transactions on Engineering Management, Vol.37, pp. 259-268

14. Chatterjee S., Lubatkin M., Schweiger D.M., Weber Y., 1992. Cultural Differences and Shareholder Value in Related Mergers: Linking Equisty and Human Capital, Strategic Management Journal, Vol.13, pp. 319-334

15. Datta D.K., 1991. Organizational Fit and Acquisition Performance: Effects of PostAcquisition Integration, Strategic Management Journal, Vol. 12(4), pp.281-298

16. Delecourt P., Fine M., 2008. Negocier une entreprise: Comment reussir ses FusionsAcquisitions, Editeur Gualino, Paris

17. Finkelstein S., Halebian J., 2002. Understanding acquisition performance: the role of transfer effects, Organization Science, vol.12(1), pp.36-47

18. Fried Y., Tiegs R.B., Naughton T.J., Ashford B.E., 1996. Managers reactions to a corporate acquisition: test of an integrative model, Journal of Organization Behavior, Vol.17, pp.401427

19. Gouali M., 2009. Fusions-Acquisitions. Les 3 Regles du Succes, Ed.D'Organisation, Paris

20. Greenwood, R., Hinings, C.R. and Brown, J. (1994), Merging professional service firms, Organization Science, Vol.5(2), pp.239-257

21. Haspeslagh P.C., Farquhar A., 1987. The Acquisition Integration Process: a Contingent Framework, $7^{\text {th }}$ Strategic Management Society Conference, Boston, MA, pp. 14-17

22. Haspeslagh P., Jemison D.B., 1991. Managing Acquisitions - Creating Value Through Corporate Renewal, Free Press, London

23. Hogan E., Overmyer-Day L., 1994. The Psychology of mergers and acquisitions, International review of industrial and organizational psychology, Vol.9, pp.248-281

24. Jemison D.B., 1988. Value Creation and Acquisition Integration: the Role of Strategic Capability Transfer în Liebcap, G., Corporate Restructuring Through Mergers, Acquisitions and Laveraged Buyouts: Advances in the Study of Entrepreneurship, Innovation and Economic Growth, Jai Press, Greenwich, pp.191-218

25. Jemison D.B., Sitkin S.B., 1986. Corporate Acquisitions: a Process Perspective, Academy of Management Review, 11(1), pp.145-163

26. Karim S., Mitchell W., 2000. Reconfiguring business ressources following acquisitions in the US medical sector, Strategic Management Journal, nr.21, pp.1061-1081

27. Leroy F., Ramantsoa B., 1997. The cognitive and behavioral dimensions of organizational learning in a merger, Journal of Management Studies, vol.34, pp.871-894

28. Marks M.L., Mirvis P.H., 1992. Rebuilding after the merger: Dealing with survivor sickness, Organizational Dynamics, Vol.21, nr.2, pp.18-35

29. Meier O., Schier G., 2006. Fusions Acquisitions- Strategie, Finance, Management, Ed. Dunod, Paris

30. Morosini P., Shane S., Singh H., 1998. National Cultural Distance and Cross-Border Acquisition Performance, Journal of International Business Studies, Vol.19, 1, pp.137-158 
31. Nahavandi A., Malekzadeh A.R., 1988. Acculturation in Mergers and Acquisitions, Academy of Management Review, Vol.13, pp.79-90

32. Olie R., 1994. Shades of Culture and institutions in international mergers, Organization Studies, Vol.15, pp.381-405

33. Pablo A.L., 1994. Determinants of Acquisition Integration Level-a Decision-Making Perspective, Academy of Management Journal, nr.37(4), pp.803-836

34. Quah P., Young S., 2005. Post-acquisition Management: A Phases Approach for Crossborder M\&As, European Management Journal, Vol.23, nr.1, pp.65-75

35. Schein E., 1993. On dialogue, culture and organizational learning, Organizational Dynamics, Vol.22, nr.2, pp.40-51

36. Schweiger D.M., DeNisi A.S., 1991. Communication with employees following a merger: a longitudinal field experiment, Academy of Management Journal, nr.34(1), pp.100-135

37. Shanley M.T., Correa M.E., 1992. Agreement Between Top Management Teams and Expectations for Post Acquisition Performance, Strategic Management Journal, nr.13, pp.245-266, available on-line:

http://www.xs4all.nl/ karhen/Papers/M\&A/Stanley\%20and\%20Correa\%20\%281992\%29.p df, accessed 04.03.2011;

38. Sherman A.J., Hart M.A., 2006. Mergers\&Acquisitions From A to Z, Ed. Amacom, New, York

39. Shrivastava P., 1986. Postmerger Integration, The Journal of Business Strategy, vol. 7, nr.1, pp. $65-76$

40. Weber Y., 1996. Corporate Culture Fit and Performance in Mergers and Acquisitions, Human Relations, Vol.49, nr.9, pp.1181-1202

41. Young M., Post J.E., 1993. Managing to communicate, communicating to manage: How leading companies communicate with employees, Organizational Dynamics, Vol.22, nr.1, pp.31-43. 